\title{
Presurgery osteoarthritis severity over 10 years in 2 Ontario prospective total knee replacement cohorts: a cohort study
}

\author{
Aileen M. Davis PhD, Selahadin Ibrahim MA, Sheilah Hogg-Johnson PhD, Dorcas E. Beaton PhD, \\ Bert M. Chesworth PhD, Rajiv Gandhi MD MSc, Nizar N. Mahomed MD DPhil, \\ Anthony V. Perruccio PhD, Vaishnav Rajgopal MD, Rosalind Wong BSc, James P. Waddell MD
}

\section{Abstract}

Background: It has been suggested that total knee replacement is being performed in people with less-severe osteoarthritis. We aimed to determine whether there were differences in the presurgery profile, symptoms and disability of 2 cohorts who underwent total knee replacement over a 10-year period.

Methods: Patients aged 18-85 years undergoing primary total knee replacement for osteoarthritis at 1 of 4 sites in Toronto and Strathroy, Ontario, were recruited in a cohort study during 2006-2008 (cohort 1) and 2012-2015 (cohort 2). Patients undergoing unicompartmental or revision arthroplasty were excluded. Demographic and health (body mass index [BMI], comorbidity) variables and osteoarthritis severity, as assessed with the Western Ontario and McMaster Universities Osteoarthritis Index (WOMAC) and the disability component of the Late-Life Function and Disability Instrument (LLFDI-D), were collected before surgery. We calculated proportions, means and standard deviations with $95 \%$ confidence intervals $(\mathrm{Cls})$ for all data. We constructed density plots by tertile score for the WOMAC pain and physical function subscales and the LLFDI-D limitation scale.

Results: There were 494 patients in cohort 1 and 251 patients in cohort 2. There were no differences in age, sex, education, living status, BMI, comorbidity, pain severity or disability between the cohorts based on overlapping $95 \%$ Cls and the density plots. More patients in cohort 1 than in cohort 2 were single (176 [35.6\%], 95\% Cl 32.5\%-41.1\% v. 63 [25.1\%], 95\% Cl 20.3\%-31.0\%). Patients in cohort 2 reported less limitation in higher-demand activities than did those in cohort 1 (mean score on LLFDI-D 62.3 [95\% CI 60.763.9] v. 59.2 [95\% Cl 58.2-60.2]).

Interpretation: The patient profile and reported osteoarthritis severity were similar in 2 cohorts that had total knee replacement over a 10 -year period. This suggests that increasing total knee replacement volumes over this period likely were not driven by these factors.

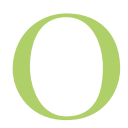

steoarthritis is a common, disabling and costly disease. ${ }^{1-4}$ When medical management of knee osteoarthritis fails, total knee replacement is recommended with the intent of alleviating pain and improving function and quality of life. ${ }^{5-7}$ Total knee replacement is one of the fastestgrowing surgical interventions in the developed world. ${ }^{8-10} \mathrm{~A}$ decade ago, an increase of $139 \%$ in the procedure between 1996/97 and 2006/07 in Canada was reported. ${ }^{11}$ An increase of $100 \%$ was reported in the United States over a similar period, ${ }^{8}$ with a projected increase of $143 \%$ by $2050 .{ }^{12}$ Demand for total knee replacement is expected to continue, with resultant ongoing challenges managing wait times for surgery ${ }^{13}$ and resources in health care systems with increasing cost constraints.

Demand for total knee replacement is increasing owing to the rising prevalence of knee osteoarthritis from aging of the population, obesity and knee injury. ${ }^{14}$ However, aging of the population and obesity account for only about $20 \%$ of the increased number of total knee replacement operations in the United States. ${ }^{8,14}$ The procedure is being performed in younger people: data from the Canadian Joint Replacement Registry indicate that the greatest increase in total knee replacement volume is among those aged $45-54$ years. ${ }^{11}$ Other investigators have suggested that total knee replacement is, perhaps inappropriately, being offered to those with less severe disease and symptoms. ${ }^{15}$ We aimed to determine whether there were differences in the demographic profile and osteoarthritis severity, defined by symptoms and disability, of 2 cohorts of patients who had total knee replacement in Ontario over a 10 -year period.

Competing interests: Rajiv Gandhi reports institutional research support received from Smith \& Nephew and Zimmer Biomet. No other competing interests were declared.

This article has been peer reviewed.

Correspondence to: Aileen Davis, adavis@uhnresearch.ca CMAJ Open 2018. DOI:10.9778/cmajo.20170164 


\section{Methods}

\section{Cohort samples}

Cohort 1 was recruited between March 2006 and March 2008, and all had their total knee replacement surgery between April 2006 and April 2008. Cohort 2 was recruited between November 2012 and March 2015 and had their total knee replacement surgery between December 2012 and April 2015. Cohort 1 was recruited from 4 tertiary care centres in Toronto: the University Health Network, Mount Sinai Hospital, St. Michael's Hospital and Sunnybrook Health Sciences Centre. Recruitment sites for cohort 2 included 3 sites: the University Health Network, St. Michael's Hospital and Strathroy Middlesex General Hospital (a community-based hospital about $250 \mathrm{~km}$ from Toronto).

Eligibility criteria were the same for the 2 cohorts. All patients were deemed surgical candidates based on the surgeon's usual criteria of radiographic severity, clinical findings, and patient symptoms and functional difficulties. All had agreed to primary total knee replacement for osteoarthritis. Additional eligibility criteria included age 18-85 years and sufficient fluency in English to complete questionnaires and consent. Exclusion criteria included total knee replacement for a condition other than osteoarthritis (e.g., injury or malignant disease), and unicompartmental or revision arthroplasty.

\section{Data collection}

Consenting patients completed questionnaires within 1 month before surgery at their preadmission clinic visit. The questionnaire elicited demographic (age, sex, education level, marital status, living alone or with others) and health (body mass index, comorbidity) information and patient-reported outcomes of symptoms and functional limitations. Comorbidity was evaluated with the disease listing (no/yes) of the American Academy of Orthopaedic Surgeons Comorbidity Questionnaire, which has been shown to be reliable and valid. ${ }^{16,17}$ Participants recorded pain severity and functional limitations (e.g., walking, getting up from a chair, climbing up and down stairs, dressing) using the Western Ontario and McMaster Universities Osteoarthritis Index (WOMAC), which has been shown to be reliable and valid. ${ }^{18,19}$ Higher-demand functional activities (i.e., participating in instrumental activities of daily living), personal roles (e.g., managing personal health, running errands, taking care of household business) and social roles (e.g., visiting friends/family, social activities, active recreation and exercise) were evaluated with the limitation scale of the disability component of the Late-Life Function and Disability Instrument (LLFDI-D), which has been shown to be reliable and valid. ${ }^{20,21}$ The WOMAC and LLFDI-D subscales were scored $0-100$, with higher scores representing less pain and functional limitation.

\section{Statistical analysis}

We calculated proportions, means and standard deviations with $95 \%$ confidence intervals (CIs) for all data for the 2 cohorts. We constructed density plots for the WOMAC pain subscale, the WOMAC physical function subscale and the LLFDI-D limitation scale by tertile for both cohorts.

\section{Ethics approval}

Written informed consent was obtained from each participant in accordance with the ethics review board that approved the study at each participating site.

\section{Results}

The derivation of the analytic sample from among patients initially enrolled or approached about the study is shown in Figure 1. The analytic sample size of cohorts 1 and 2 was 494 and 251, respectively. In both cohorts, the patients were on average 65 years of age, and both included more women than men (Table 1). Most had high school or greater education, and about $23 \%$ lived alone. A total of 176 patients $(35.6 \%)$ in cohort 1 were single, compared to $63(25.1 \%)$ in cohort 2 ; this was the only demographic variable for which the $95 \%$ CIs did not overlap, although the CIs for sex overlapped by only 0.3 percentage points.

There were no differences in health variables between the 2 cohorts. A total of 407 patients (82.4\%) in cohort 1 and 194 $(77.3 \%)$ of those in cohort 2 were overweight or obese. Eighty percent of patients in both cohorts reported at least 1 comorbid condition.

\section{Osteoarthritis severity}

There was no difference in disease severity between the cohorts based on the mean scores for the pain and physical function subscales of the WOMAC. The mean score on the LLFDI-D limitation scale was 59 for cohort 1 and 62 for cohort 2, and the CIs did not overlap. The density plots for each subscale are shown in Figure 2, Figure 3 and Figure 4. The plots for WOMAC pain and physical function across tertiles of scores showed similar distributions for the 2 cohorts. The plots for the lower and upper tertile of LLFDI-D limitation showed similar distributions for the cohorts, but the middle tertile for cohort 1 had a more restricted score range and higher density than that for cohort 2. Specifically, the middle tertile scores for cohort 1 ranged from 50 to 65 , with peak density of 17 , whereas the scores for cohort 2 ranged from 50 to 70 , with peak density of 12 .

\section{Interpretation}

Although there were minor differences in marital status and presurgery ability to perform higher-demand activities between our 2 cohorts of patients who had total knee replacement for osteoarthritis, demographic characteristics, obesity and comorbidity, and severity of osteoarthritis symptoms and disability were consistent between the cohorts even though they were recruited at different times over a 10-year period. It is, however, important to note that the CI for sex overlapped by less than $1 \%$, and the CIs for both marital status and limitation in high-demand activities missed overlapping by only $1 \%$. The reason for this trend toward a larger proportion of men in the cohort recruited in the later period is not clear, but research suggests that men are more likely than women to access orthopedic surgeons in Ontario. ${ }^{22}$ 
Marital status is unlikely to influence whether a patient has total knee replacement, and, although the mean score for LLFDI-D limitation in high-demand activities was 3 points lower in the earlier cohort than in the later cohort, this difference is not clinically meaningful. ${ }^{21}$ There were no differences in scores on the WOMAC pain and physical function subscales between the cohorts. Our findings from these samples, therefore, do not support that increased total knee replacement volumes are in part due to those with less osteoarthritis severity having this surgery.

There was a 4-year gap in recruitment of our 2 cohorts, and the cohorts had 2 recruitment sites in common. The sample characteristics of our cohorts are similar to those of other total knee replacement cohorts, including an Ontario cohort of 1578 patients undergoing total knee replacement described in 2008. ${ }^{23}$ Patients undergoing total knee replacement generally are in their 60s, are overweight or obese, and have comorbidities.
Symptom and disability severity and the timing of total knee replacement for people with osteoarthritis are subject to debate. As with other cohorts, ${ }^{23}$ our data show that pain and disability scores before knee replacement largely reflect the available score range of the WOMAC and LLFDI-D. Some investigators have suggested that such data indicate that patients with too little pain and disability are having total knee replacement. ${ }^{15}$ However, osteoarthritis pain is known to fluctuate; there is a constant, less-intense pain accompanied by more severe intermittent pain. ${ }^{24}$ This suggests that a single pain rating based on the prior week may not reflect the pain experience for a patient. In addition, Judge and colleagues ${ }^{25}$ showed that patients with less severe osteoarthritis symptoms and disability benefit from and are just as satisfied with their outcome as those with more severe symptoms and disability. Research also shows that, although patients with severe symptoms and disability benefit, they do not achieve the gains from total knee replacement of those who report less pain and

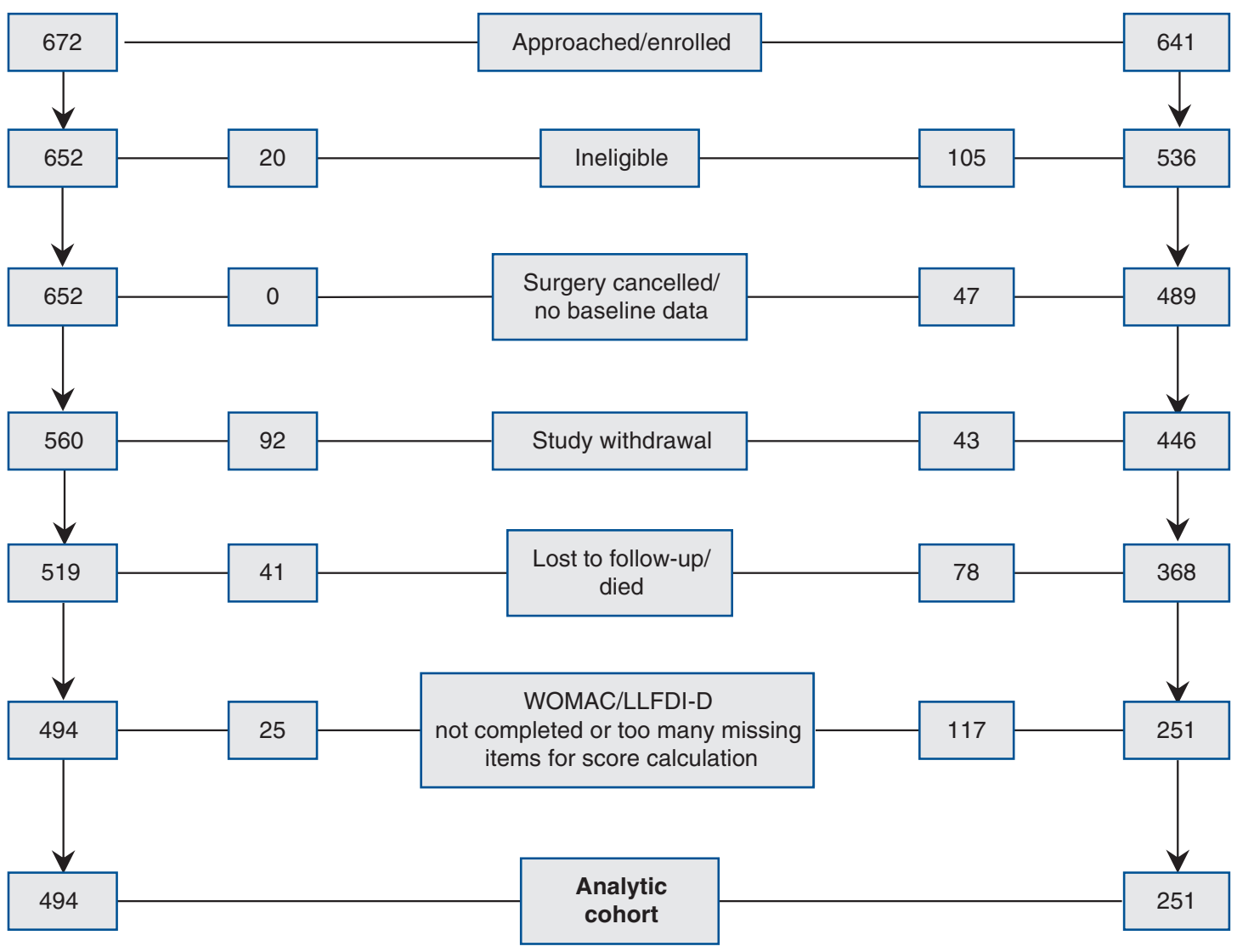

Figure 1: Flow diagram showing derivation of the analytic cohorts. Note: LLFDI-D = Late-Life Function and Disability Instrument disability component, WOMAC = Western Ontario and McMaster Universities Osteoarthritis Index. 
functional limitations. ${ }^{23}$ These data with low-quality evidence for appropriateness, ${ }^{26}$ in sum, may contribute to the less than satisfactory application of appropriateness criteria for total knee replacement to date. ${ }^{15,27}$ Decisions to offer and proceed with total knee replacement are much more complex. ${ }^{28}$ There is increasing recognition of the need to consider the patient's response (or lack thereof) to adequate conservative management, including weight management, exercise and pharmacotherapy, ${ }^{29-32}$ as well as pain and disability and their impact on quality of life.

\begin{tabular}{|c|c|c|}
\hline \multirow[b]{2}{*}{ Variable } & \multicolumn{2}{|c|}{ No. $(\%)$ of patients* } \\
\hline & $\begin{array}{c}\text { Cohort } 1 \text { (earlier) } \\
\qquad n=494\end{array}$ & $\begin{array}{c}\text { Cohort } 2 \text { (later) } \\
\quad n=251\end{array}$ \\
\hline \multicolumn{3}{|l|}{ Age, yr } \\
\hline Mean \pm SD $(95 \% \mathrm{Cl})$ & $64.9 \pm 10.2(64.0-65.8)$ & $65.1 \pm 9.2(63.9-66.2)$ \\
\hline Range & $35-87$ & $43-90$ \\
\hline Male sex; 95\% Cl & 171 (34.6); 30.6-38.9 & 112 (44.6); 38.6-50.1 \\
\hline \multicolumn{3}{|l|}{ Education; $95 \% \mathrm{Cl}$} \\
\hline High school or greater & $326(66.0) ; 62.2-70.6$ & $180(71.7) ; 66.4-77.5$ \\
\hline Missing & $4(0.8)$ & $2(0.8)$ \\
\hline \multicolumn{3}{|l|}{ Marital status; $95 \% \mathrm{Cl} \dagger$} \\
\hline Single & 176 (35.6); 32.5-41.1 & $63(25.1) ; 20.3-31.0$ \\
\hline Missing & $14(2.8)$ & $2(0.8)$ \\
\hline \multicolumn{3}{|l|}{ Living status; 95\% Cl } \\
\hline Lives alone & $121(24.5) ; 20.9-28.5$ & 49 (19.5); 15.7-25.8 \\
\hline Missing & $0(0)$ & $9(3.6)$ \\
\hline \multicolumn{3}{|l|}{ Body mass index; $95 \% \mathrm{Cl}$} \\
\hline Underweight & $2(0.4) ; 0.1-1.5$ & $1(0.4) ; 0.1-2.3$ \\
\hline Normal & $83(16.8) ; 13.8-20.4$ & 49 (19.5); 15.5-25.5 \\
\hline Overweight & 184 (37.2); 33.2-41.8 & 76 (30.3); 25.7-37.2 \\
\hline Obese & $223(45.1) ; 40.9-49.6$ & $118(47.0) ; 24.2-54.6$ \\
\hline Missing & $2(0.4)$ & $7(2.8)$ \\
\hline$\geq 1$ comorbid condition; $95 \% \mathrm{Cl}$ & 394 (79.8); 76.0-83.1 & 201 (80.1); 74.2-84.5 \\
\hline Hypertension; 95\% Cl & 242 (49.0); 44.6-53.4 & $121(48.2) ; 42.1-54.4$ \\
\hline Cardiovascular disease; $95 \% \mathrm{Cl}$ & $31(6.3) ; 4.5-8.8$ & $21(8.4) ; 5.5-12.5$ \\
\hline Diabetes; 95\% Cl & $71(14.4) ; 11.5-17.4$ & $37(14.7) ; 10.9-19.7$ \\
\hline \multicolumn{3}{|l|}{ WOMAC pain $\ddagger$} \\
\hline Mean score \pm SD $(95 \% \mathrm{Cl})$ & $47.8 \pm 17.8(46.2-49.4)$ & $49.3 \pm 20.0(46.8-51.8)$ \\
\hline Range & $0-100$ & $0-100$ \\
\hline Missing & $11(2.2)$ & $3(1.2)$ \\
\hline \multicolumn{3}{|l|}{ WOMAC physical function $\ddagger$} \\
\hline Mean score \pm SD $(95 \% \mathrm{Cl})$ & $50.3 \pm 18.5(48.6-51.9)$ & $50.3 \pm 19.4(47.9-52.7)$ \\
\hline Range & $0-96$ & $0-99$ \\
\hline Missing & $8(1.6)$ & $5(2.0)$ \\
\hline \multicolumn{3}{|l|}{ LLFDI-D limitation†‡ } \\
\hline Mean score \pm SD $(95 \% \mathrm{Cl})$ & $59.2 \pm 11.0(58.2-60.2)$ & $62.3 \pm 12.9(60.7-63.9)$ \\
\hline Range & $23-100$ & $19-100$ \\
\hline Missing & $47(9.5)$ & $5(2.0)$ \\
\hline \multicolumn{3}{|c|}{$\begin{array}{l}\text { Note: } \mathrm{Cl}=\text { confidence interval, LLFDI-D = Late-Life Function and Disability Instrument disability component, SD = standard } \\
\text { deviation, WOMAC = Western Ontario and McMaster Universities Osteoarthritis Index. } \\
{ }^{*} \text { Except where noted otherwise. } \\
+95 \% \text { Cls do not overlap. } \\
\text { †Scored } 0-100 \text {, with higher scores indicating less pain and better function. }\end{array}$} \\
\hline
\end{tabular}




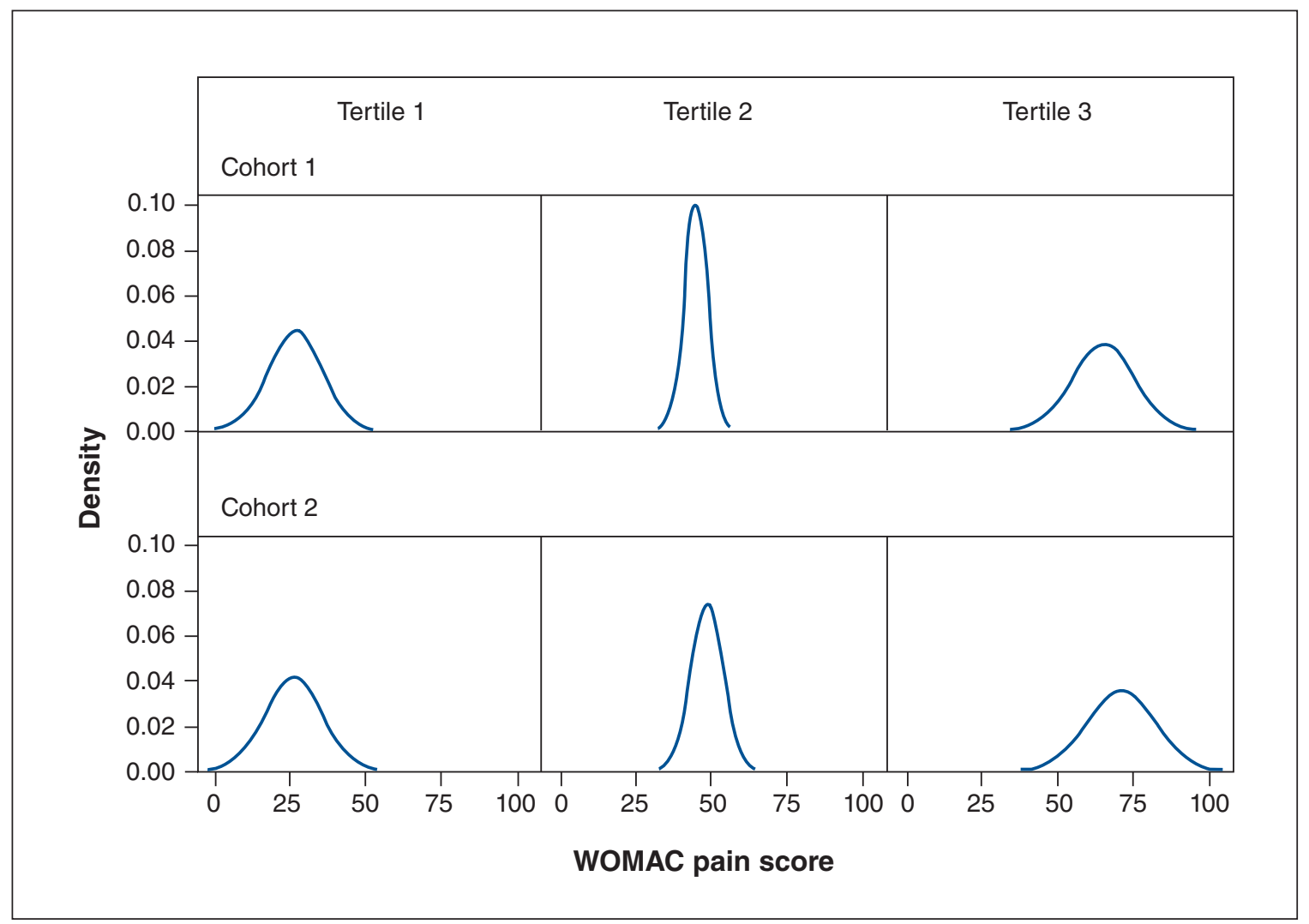

Figure 2: Density plots showing distribution of presurgery Western Ontario and McMaster Universities Osteoarthritis Index (WOMAC) pain scores for cohorts 1 and 2 by tertile. $0=$ no pain, $100=$ extreme pain.

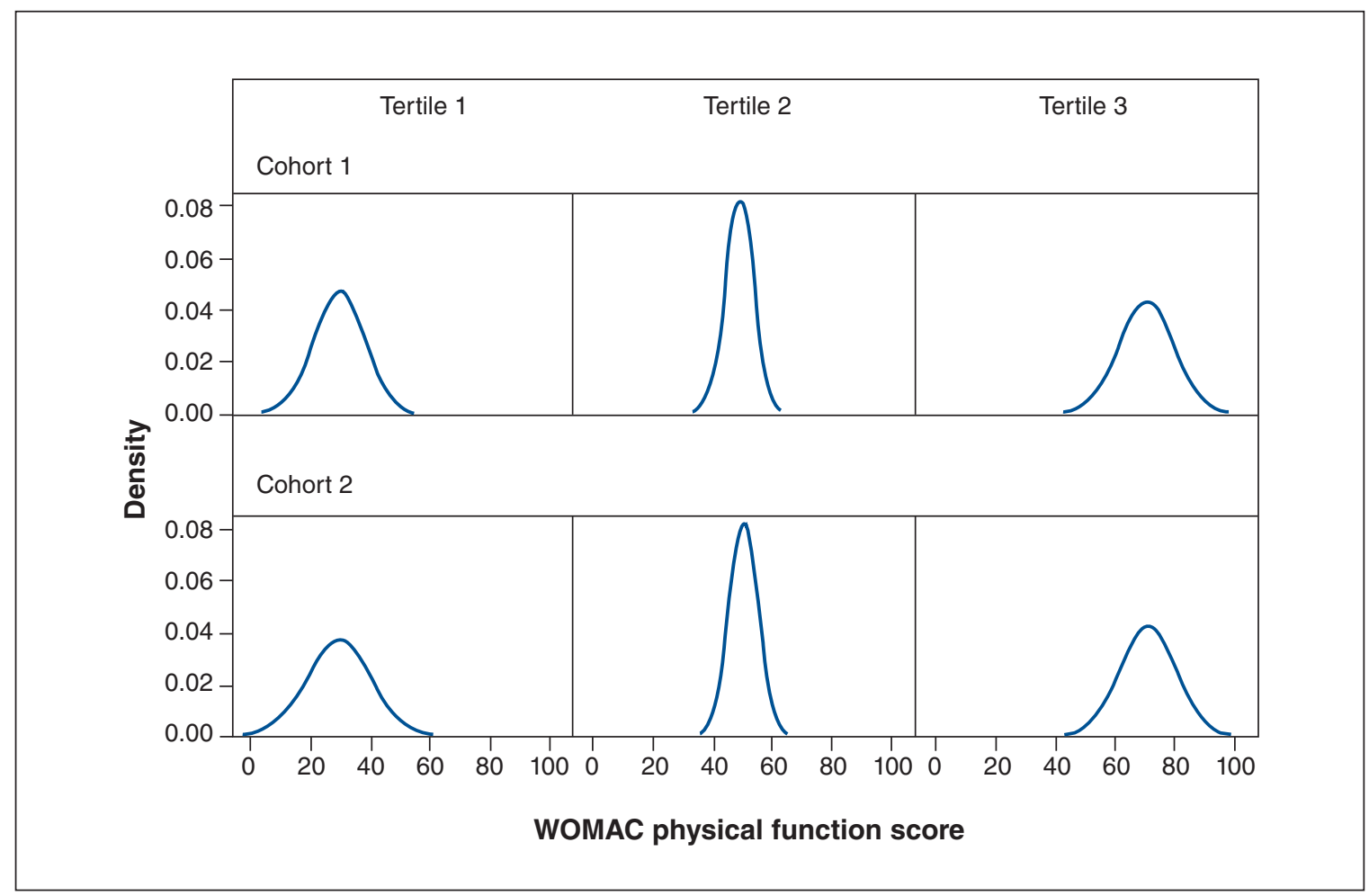

Figure 3: Density plots showing distribution of presurgery Western Ontario and McMaster Universities Osteoarthritis Index (WOMAC) physical function scores for cohorts 1 and 2 by tertile. $0=$ extreme difficulty, $100=$ no difficulty. 


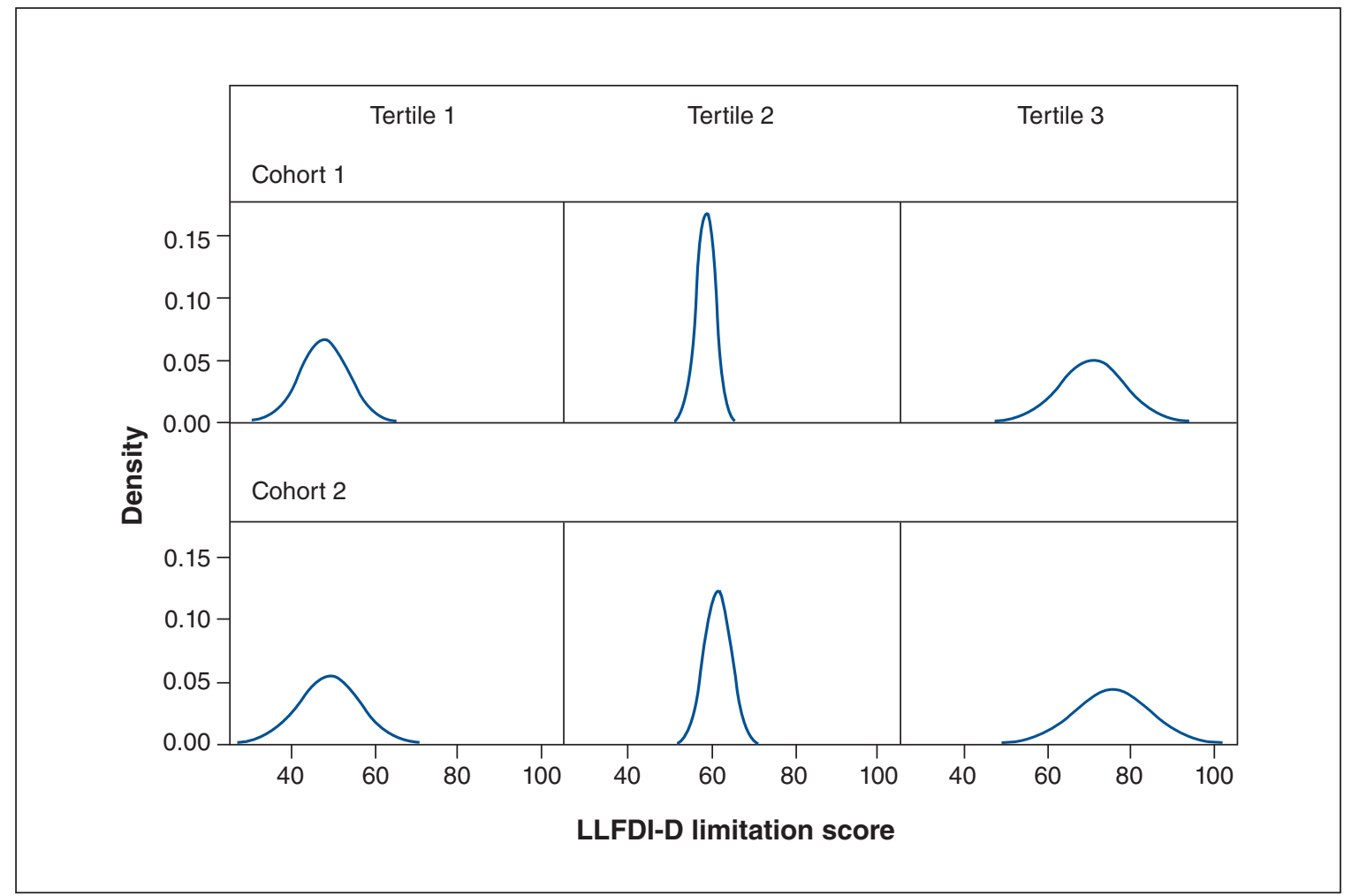

Figure 4: Density plots showing distribution of presurgery limitation scores on the disability component of the Late-Life Function and Disability Instrument (LLFDI-D) for cohorts 1 and 2 by tertile. $0=$ no limitation, $100=$ extreme limitation.

\section{Limitations}

Thirty percent of cohort 2 had incomplete outcome measures or did not complete 1 of the outcome measures, which precluded their inclusion in the study. The reasons for this are not clear, but we cannot discount that the exclusion of these patients limits the generalizability of our findings. Our sample included only patients fluent in English owing to the need to complete the questionnaires, and, therefore, the results must be interpreted in the context of this patient group. A large proportion of people in both cohorts were highly educated, and our cohort may differ from others in this regard. However, Canada has been reported to have the highest proportion of people with higher education (i.e., more than high school), with Canadian women accounting for the highest proportion, ${ }^{33}$ so generalizability to the Canadian population is likely less problematic. In addition, although the age distribution of our cohorts does not support a shift to increased numbers of younger people having total knee replacement, younger people may have declined to participate in the study. Finally, our data are based on 2 cohorts recruited largely in tertiary centres in Toronto. Although the outcomes of patients in community and academic centres are similar, ${ }^{34}$ the presurgery profile of patients having surgery in community versus academic centres may differ.

\section{Conclusion}

Our data indicate that the demographic profile and symptom and disability severity of people who had total knee replace- ment for osteoarthritis were unchanged over a 10 -year period. Thus, it is unlikely that these factors are related to the increased volumes of total knee replacement procedures. Although this work needs to be replicated in other regions and with larger samples, tackling the rising volumes and associated costs of total knee replacement likely needs a multifaceted strategy that addresses prevention of knee osteoarthritis and access to and delivery of evidence-based conservative management that may limit or delay the progression of knee osteoarthritis symptoms and disability.

\section{References}

1. MacLean CH. Quality indicators for the management of osteoarthritis in vulnerable elders. Ann Intern Med 2001;135:711-21.

2. Lawrence RC, Felson DT, Helmick CG, et al.; National Arthritis Data Workgroup. Estimates of the prevalence of arthritis and other rheumatic conditions in the United States. Part II. Arthritis Rheum 2008;58:26-35.

3. Bitton R. The economic burden of osteoarthritis. Am 7 Manag Care 2009;15 (Suppl 8):S230-5.

4. Life with arthritis in Canada: a personal and public health challenge. Ottawa: Public Health Agency of Canada; 2010.

5. Rissanen P, Aro S, Sintonen H, et al. Costs and cost-effectiveness in hip and knee replacements. A prospective study. Int 7 Technol Assess Health Care 1997; 13: 575-88.

6. Günther KP. Surgical approaches for osteoarthritis. Best Pract Res Clin Rheumatol 2001;15:627-43.

7. Davis AM, Perruccio AV, Ibrahim S, et al. The trajectory of recovery and the inter-relationships of symptoms, activity and participation in the first year following total hip and knee replacement. Osteoarthritis Cartilage 2011;19:1413-21.

8. Losina E, Thornhill TS, Rome BN, et al. The dramatic increase in total knee replacement utilization rates in the United States cannot be fully explained by growth in population size and the obesity epidemic. 7 Bone foint Surg Am 2012; 94:201-7. 
9. Leskinen J, Eskelinen A, Huhtala H, et al. The incidence of knee arthroplasty for primary osteoarthritis grows rapidly among baby boomers: a populationbased study in Finland. Arthritis Rheum 2012;64:423-8.

10. Stamp LK, Haslett J, Chapman P, et al. Rates of joint replacement surgery in New Zealand, 1999-2015: a comparison of rheumatoid arthritis and osteoarthritis. F Rheumatol 2017;44:1823-7.

11. Hip and knee replacements in Canada - Canadian Joint Replacement Registry (CFRR) 2008-2009 annual report. Ottawa: Canadian Institute for Health Information; 2009.

12. Inacio MCS, Paxton EW, Graves SE, et al. Projected increase in total knee arthroplasty in the United States - an alternative projection model. Osteoarthritis Cartilage 2017;25:1797-803.

13. Wait times for priority procedures in Canada, 2017. Ottawa: Canadian Institute for Health Information; 2017.

14. Wallace IJ, Worthington S, Felson DT, et al. Knee osteoarthritis has doubled in prevalence since the mid-20th century. Proc Natl Acad Sci US A 2017;114: 9332-6.

15. Riddle DL, Jiranek WA, Hayes CW. Use of a validated algorithm to judge the appropriateness of total knee arthroplasty in the United States: a multicenter longitudinal cohort study. Arthritis Rheumatol 2014;66:2134-43.

16. Sangha O, Stucki G, Liang MH, et al. The Self-Administered Comorbidity Questionnaire: a new method to assess comorbidity for clinical and health services research. Arthritis Rheum 2003;49:156-63.

17. Hunsaker FG, Cioffi DA, Amadio PC, et al. The American Academy of Orthopaedic Surgeons outcomes instruments: normative values from the general population. F Bone foint Surg Am 2002;84-A:208-15.

18. Bellamy N, Buchanan WW, Goldsmith $\mathrm{CH}$, et al. Validation study of WOMAC: a health status instrument for measuring clinically important patient relevant outcomes to antirheumatic drug therapy in patients with osteoarthritis of the hip or knee. F Rheumatol 1988;15:1833-40.

19. McConnell S, Kolopack P, Davis AM. The Western Ontario and McMaster Universities Osteoarthritis Index (WOMAC): a review of its utility and measurement properties. Artbritis Rheum 2001;45:453-61.

20. Jette AM, Haley SM, Coster WJ, et al. Late life function and disability instrument: I. Development and evaluation of the disability component. 7 Gerontol $A$ Biol Sci Med Sci 2002;57:M209-16.

21. Beauchamp MK, Schmidt CT, Pedersen MM, et al. Psychometric properties of the Late-Life Function and Disability Instrument: a systematic review. $B M C$ Geriatr 2014;14:12.

22. Canizares M, Davis AM, Badley EM. The pathway to orthopaedic surgery: a population study of the role of access to primary care and availability of orthopaedic services in Ontario, Canada. BM7 Open 2014;4:e004472.

23. Chesworth BM, Mahomed NN, Bourne RB, et al.; OJRR Study Group. Willingness to go through surgery again validated the WOMAC clinically important difference from THR/TKR surgery. 7 Clin Epidemiol 2008;61:907-18.

24. Hawker GA, Stewart L, French MR, et al. Understanding the pain experience in hip and knee osteoarthritis - an OARSI/OMERACT initiative. Osteoarthritis Cartilage 2008;16:415-22.

25. Judge A, Arden NK, Price A, et al. Assessing patients for joint replacement: Can pre-operative Oxford hip and knee scores be used to predict patient satisfaction following joint replacement surgery and to guide patient selection? $\mathcal{F}$ Bone foint Surg Br 2011;93:1660-4.
26. Gademan MG, Hofstede SN, Vliet Vlieland TP, et al. Indication criteria for total hip or knee arthroplasty in osteoarthritis: a state-of-the-science overview. BMC Musculoskelet Disord 2016;17:463.

27. Ghomrawi HM, Alexiades M, Pavlov H, et al. Evaluation of two appropriatenes criteria for total knee replacement. Arthritis Care Res (Hoboken) 2014;66:1749-53.

28. Dieppe P, Lim K, Lohmander S. Who should have knee joint replacement surgery for osteoarthritis? Int 7 Rheum Dis 2011;14:175-80.

29. McAlindon TE, Bannuru RR, Sullivan MC, et al. OARSI guidelines for the nonsurgical management of knee osteoarthritis. Osteoarthritis Cartilage 2014;22:363-88.

30. Skou ST, Roos EM, Laursen MB, et al. A randomized, controlled trial of total knee replacement. N Engl 7 Med 2015;373:1597-606.

31. Hawker G, Bohm ER, Conner-Spady B, et al. Perspectives of Canadian stakeholders on criteria for appropriateness for total joint arthroplasty in patients with hip and knee osteoarthritis. Arthritis Rheumatol 2015;67:1806-15.

32. Schmitt J, Lange T, Günther KP, et al. Indication criteria for total knee arthroplasty in patients with osteoarthritis - a multi-perspective consensus study. Z Orthop Unfall 2017;155:539-48.

33. Education at a glance 2016: OECD indicators. Paris: Organisation for Economic Co-operation and Development; 2016.

34. Gandhi R, Tso P, Davis A, et al. Outcomes of total joint arthroplasty in academic versus community hospitals. Can 7 Surg 2009;52:413-6.

Affiliations: Division of Health Care and Outcomes Research (Davis, Perruccio, Wong), Krembil Research Institute and Institute of Health Policy, Management and Evaluation, Dalla Lana School of Public Health, University of Toronto; Institute for Work and Health (Ibrahim, Beaton); Canadian Memorial Chiropractic College (Hogg-Johnson); Dalla Lana School of Public Health (Hogg-Johnson), University of Toronto; Institute of Health Policy, Management and Evaluation (Beaton), Dalla Lana School of Public Health, University of Toronto, Toronto, Ont.; Department of Physical Therapy (Chesworth), Western University, London, Ont.; Arthritis Program (Gandhi, Mahomed), Toronto Western Hospital and Division of Orthopaedic Surgery, University of Toronto, Toronto, Ont.; Orthopaedic Surgery (Rajgopal), Strathroy Middlesex General Hospital, Strathroy, Ont.; Division of Orthopaedic Surgery (Waddell), St. Michael's Hospital and University of Toronto, Toronto, Ont.

Contributors: Aileen Davis drafted the manuscript. All of the authors contributed to the conception and design of the work, data acquisition, data analysis or interpretation, and revising the manuscript critically for important intellectual content, gave final approval of the version to be published and agreed to be accountable for all aspects of the work.

Funding: This work was funded by operating grants from the Canadian Institutes of Health Research (grant 77518) and The Arthritis Society.

Supplemental information: For reviewer comments and the original submission of this manuscript, please see www.cmajopen.ca/content/6/3/ E269/suppl/DC1. 